\title{
Modeling Chilling Influence on Cumulative Flowering: A Case Study Using 'Tifblue Rabbiteye Blueberry
}

\author{
D.S. NeSmith ${ }^{1}$ and D.C. Bridges ${ }^{2}$ \\ The University of Georgia, Georgia Station, Griffin, GA 30223-l 797 \\ Additional index words. Vaccinium ashei
}

\begin{abstract}
A Weibull distribution function was used to develop a model for estimating cumulative flowering and the distribution of flowering of 'Titblue' rabbiteye blueberry (Vaccinium Ashei Reade) as a function of growing degree days (GDD) following exposure to chilling temperatures for 300 to 1200 hours. Controlled chilling and flowering conditions were imposed on blueberry plants to obtain data for model development. Once developed, the model was validated using independent data sets from the literature. Given information concerning chilling and historical GDD, the model can be used to predict the onset of flowering, cumulative flowering, total number of flowers, and flower frequency at discrete intervals. The techniques developed likely will be applicable to a range of fruit species in which chilling influences flowering habit.
\end{abstract}

Rabbiteye blueberries are produced extensively in the southeastern United States; however, the occurrence of chilling temperatures is variable, and depending on the cultivar, chilling may or may not be sufficient to promote optimum flower and fruit development (Lyrene and Cracker, 1983; Spiers and Draper, 1974). Although the chilling requirement for "normal" flower development of 'Tifblue' is reported to be 550 to 650 chill hours (Austin et al., 1982; Krewer et al., 1989; Spiers, 1976), the time to $50 \%$ bloom (generally defined by $50 \%$ of the flowers having reached the stage of fully expanded corollas) for 'Tifblue' decreases with increased chilling duration. A static description of development in response to chilling by a single criterion such as $50 \%$ bloom does not provide the necessary information to make management decisions over the total flowering period that a more dynamic description, such as cumulative flower development, would.

The reporting of a single-value development index is consistent with much of the plant science literature, where a single mean value of plant development rate or time is reported with a measure of dispersion such as variance or SD. Techniques employing the use of a mean rate (or time) with a variance as a measure of dispersion are based on the assumption that the occurrence of phenological events is normally distributed about the mean with respect to time. Phenological events such as germination and flowering are typically skewed toward longer development time (Beddows, 1968; Bridges et al., 1989; Gaswiler, 1971; Veerhoff, 1940). Therefore, techniques that describe the cumulative frequency of phenological events, such as flowering, may prove more useful than single-value indices.

Recently, cumulative Weibull functions, a type of distribution function, have proven useful for describing the distribution of phenological events with respect to time (Bridges and Chandler, 1989; Bridges et al., 1989; Brown, 1987; Brown and Mayer, 1988). The Weibull function provides a meaningful measure of central tendency and dispersion when the conditions of strict

Received for publication 9 Dec. 1991. Accepted for publication 20 Apr. 1992. A contribution of the Univ. of Georgia Agr. Expt. Sta., Georgia Station, Griffin. This research was supported by state and Hatch Act funds allocated to the Georgia Agr. Expt. Stas. The cost of publishing this paper was defrayed in part by the payment of page charges. Under postal regulations, this paper therefore must be hereby marked advertisement solely to indicate this fact.

'Dept. of Horticulture.

${ }^{2}$ Dept. of Agronomy. randomness and symmetry are not satisfied. The Weibull function is especially well suited for describing the cumulative frequency of events within a -population in which the individuals exist in either of two states, in this case flowering or not flowering, and where rapid transition occurs between the states (Brown and Mayer, 1988).

The rate and duration of plant development depends on temperature and time. A common means of normalizing temperature effects on development is the use of thermal time or heat units (Ritchie and NeSmith, 1991). The use of thermal time instead of real or calendar time tends to produce experimental results that are transferable and comparable, even though the results may be from specific locations and environments. Couvillon and Erez (1985) used heat units in describing flowering response to chilling of several fruit species other than blueberry. The objectives of our research were to quantify cumulative flower development of rabbiteye blueberries in response to chilling and to develop a model that describes cumulative flowering in terms of chilling hours and heat units received after chilling.

\section{Materials and Methods}

Two-year-old potted 'Tifblue' blueberry plants were defoliated on 14 Nov. 1990, before any chilling temperatures $(<7 \mathrm{C})$ occurred, and were placed in darkness at 3 to $4 \mathrm{C}$. Plants were removed from the cooler after receiving 350, 520, 760, or 1150 $\mathrm{h}$ of chilling and placed in a greenhouse for forcing. Daily minima and maxima in the greenhouse averaged 19 and 24C, respectively. Each chilling experimental unit consisted of 10 plants. All flower buds on plants were counted weekly, and buds that had developed to the point of fully elongated and expanded corollas were tallied to determine cumulative flowering. The data were translated to percent of the total number of flowers and were reported relative to the sum of heat units after chilling. Daily heat units, or growing degree days (GDD), were calculated using the following equation:

$$
\text { GDD }=\left[\left(\mathrm{T}_{\min }+\mathrm{T}_{\max }\right) / 2\right]-\mathrm{T}_{\text {base }}
$$

where $\mathrm{T}_{\min }=$ daily minimum temperature, $\mathrm{T}_{\max }=$ daily maximum temperature, and $\mathrm{T}_{\text {basc }}=$ base temperature, i.e., 7C. The base temperature selection was made after reports (Anstey, 1966; Rom and Arrington, 1966) indicating temperatures near 7C were

Abbreviation: GDD, growing degree day. 
likely the base temperatures for several fruit species, other than blueberry. To our knowledge, a base temperature for rabbiteye blueberry has not been reported, and additional experiments are necessary to accurately determine that temperature.

A cumulative Weibull distribution function having three parameters (Johnson and Kotz, 1970) was fitted to the mean cumulative flowering data of plants from each experimental chilling regime. The function was of the form

$$
\mathrm{Y}=1-\operatorname{EXP}\{-[(\mathrm{x}-\gamma) / \eta] \beta\}
$$

where $\mathrm{Y}=$ cumulative bloom at GDD $\mathrm{x}, \gamma=$ the location parameter, or GDD immediately preceding the beginning of bloom, $7=$ the bloom rate constant, and $\beta=$ a shape parameter. Parameter estimates were obtained by an iterative Marquardt method nonlinear regression technique (Ihnen and Goodnight, 1985). Starting estimates for each of the parameters were obtained by a linear transformation after that of Mann et al. (1974). Equations to predict $\gamma, \eta$, and $\beta$ for any chilling period from 300 to 1200 chilling hours were developed by regressing each of these Weibull function parameters against chilling hours, the independent variable. The predicted equations for parameters $\gamma, \eta$, and $\beta$ were of the form:

$$
\mathrm{Y}=\mathrm{B}_{1} * \operatorname{EXP}\left(\mathrm{B}_{2} * \mathrm{X}\right)+\mathrm{B}_{3}
$$

where, $\mathrm{Y}=$ either Weibull parameter $\gamma, \eta$, or $\beta$, and $\mathrm{B}_{1}, \mathrm{~B}_{2}$, and $\mathrm{B}_{3}$ are coefficient estimates from the regression. Therefore, parameters $\gamma, \eta$, and $\beta$, for the cumulative Weibull function (eq. [2]) were estimated from experimental data as a function of chilling hours. A family of cumulative distribution curves was developed to depict cumulative flowering as a function of chilling hours and GDD after chilling. Likewise, a probability density function (PDF) was developed by taking the derivative of the cumulative distribution function (CDF) (Cohen et al., 1984).

The final model was written using the Statistical Analysis System (SAS, Cary, N.C.) and included the Weibull functions, CDF and PDFs, the equations to estimate $\gamma, \eta$, and $\beta$, and other supportive code. The model was validated by comparing the predicted bloom with observed values from the current investigation and other controlled environment experiments previously reported in the literature.

\section{Results and Discussion}

Cumulative flowering or bloom, and the respective curves as derived from the Weibull function applied to the various experimental chilling regimes were plotted as a function of GDD after chilling (Fig. 1). The Weibull function parameters for 350, 520, 760, and 1150 chill hours and the respective regression lines were derived (Fig. 2) based on regression analysis for each parameter (Table 1). The Weibull function is an emperical distribution function. As such, its parameters are unitless and have no explicit biological meaning. However, biological inference can be made based on the application.

The location parameter $(\gamma)$ decreased as the number of chilling hours increased, indicating that the onset of flowering occurred sooner after the chilling period ended. Similarly, decreasing the number of chilling hours resulted in delayed flowering. Extrapolating the equation relating $\gamma$ to chilling hours beyond the range 350-1150 revealed that as the number of chilling hours approached zero the value of $\gamma$ approached the sum of $B_{1}$ and $\mathrm{B}_{2}$, or $\approx 1070$. Therefore, the regression equation indicates that at least one bud would be expected to bloom after 1070 GDD

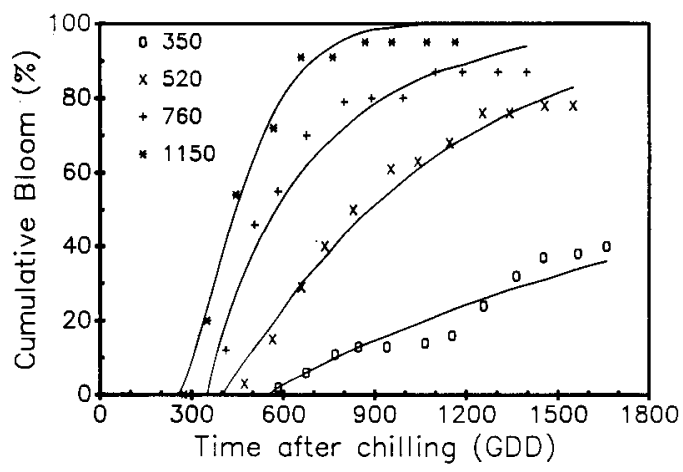

Fig. 1. Cumulative bloom of 'Tifblue' rabbiteye blueberries as a function of chill hours and GDD after chilling. Data points are experimental observations for chilling regimes of 3.50, 520,760, and $1150 \mathrm{~h}<7 \mathrm{C}$, and solid lines are Weibull function estimates from the data.
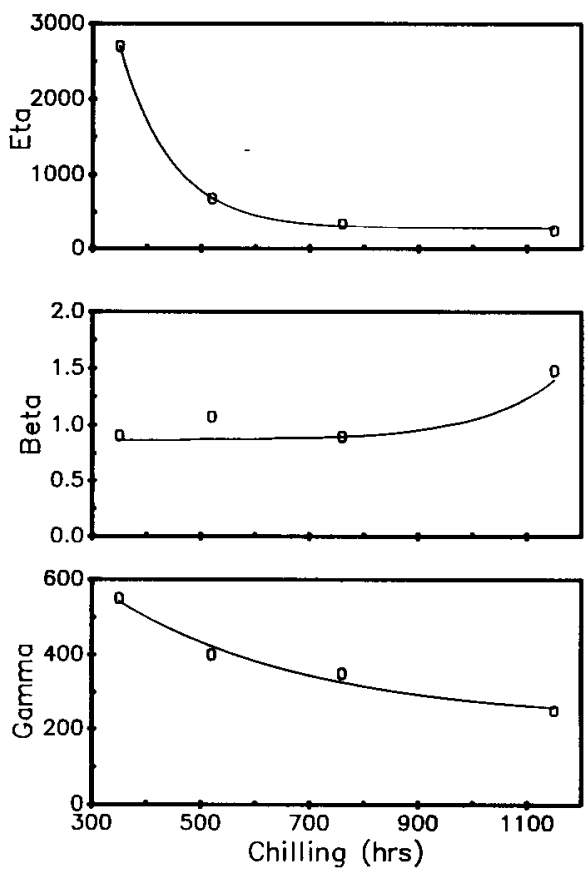

Fig. 2. Estimates of Weibull parameters $\gamma, \beta$, and $\eta$ as a function of chill hours. Data points are the actual Weibull parameters generated from chilling regimes of $350,520,760$, and $1150 \mathrm{~h}<7 \mathrm{C}$, and solid lines are generated from the regression information listed in Table 1 .

Table 1. Regression coefficients and significance for Weibull function parameters $\gamma, \eta$, and $\beta$ as a function of chill hours. The nonlinear regression equation applied to each Weibull parameter was of the form $\mathrm{Y}=\mathrm{B}_{1} * \operatorname{EXP}\left(\mathrm{B}_{2} * \mathrm{X}\right)+\mathrm{B}_{3}$, where $\mathrm{Y}$ is Weibull parameter $\gamma, \eta$, or $\beta$; $X$ is chill hours; and $B_{1}, B_{2}$, and $B_{3}$ are regression coefficients.

\begin{tabular}{lcrcc}
\hline \hline & \multicolumn{4}{c}{ Regression coefficient } \\
\cline { 2 - 5 } Weibull parameter & $\mathrm{B}_{1}$ & \multicolumn{1}{c}{$\mathrm{B}_{2}$} & $\mathrm{~B}_{3}$ & $r^{2}$ \\
\hline$\gamma$ & $8.4 \times 10^{2}$ & $-2.8 \times 10^{-3}$ & $2.2 \times 10^{2}$ & 0.97 \\
$\eta$ & $9.2 \times 10^{4}$ & $-1.0 \times 10^{-2}$ & $2.7 \times 10^{2}$ & 0.99 \\
$\beta$ & $1.5 \times 10^{-4}$ & $7.1 \times 10^{-3}$ & $9.5 \times 10^{-1}$ & 0.90 \\
\hline
\end{tabular}

even in the absence of chilling. Increasing chilling hours from 350 to $520 \mathrm{~h}$ resulted in a rapid decline in $\eta$, the reciprocal of rate (time). Further increases in chilling hours resulted in little change in $\eta$. In fact, as chilling hours increased beyond $\approx 600$ 
$\mathrm{h}, \eta$ approached an asymptotic minimum of $\approx 275$. Therefore, the rate at which flowering proceeded increased with increasing chilling hours and approached a maximum value. Conversely, decreasing chilling hours resulted in an increasing $\eta$, or greatly reduced rate of development. The rate of flowering indicated by $\eta$ is a population-level rate and does not reflect a temperature-dependent rate for an individual flower bud or plant, but rather reflects the progression of cumulative flowering for the population. Parameter $\beta$ is a shape parameter that is related to the skewness and kurtosis of the distribution. For a given value of $\eta$, the time (GDD) to $63.2 \%$ of cumulative flowering is by definition constant regardless of the value of $\beta$, where $\beta$ is inversely proportional to $\eta$ (Brown and Mayer, 1988). Values of $\beta$ between 3.25 and 3.61 yield distributions that approximate the normal distribution. Values of $\beta<3.21$, as occurred here, indicate that the distribution is skewed toward longer times, or right-skewed. Therefore, decreasing values of $\beta$ result in greater skewing toward long times, meaning the flowering period is greatly extended. The skewing observed here invalidates the traditional use of means with SDs, since flowering was not normally distributed with respect to time.

For these experiments, chilling hours were calculated by summing the number of hours that the plants were exposed to constant chilling temperatures in a controlled-environment chamber. Determining chilling and/or the end of the resting phase in the field where variable temperatures result in an intermittent chilling process is more difficult. However, several approaches have been devised and tested (Linvill, 1990; Richardson et al., 1974; Sanders, 1976; Spiers, 1976). Determining the most appropriate computational method for calculating chilling was not the primary objective of this paper. However, the model presented can easily be parameterized to use chilling days, chilling hours, or chilling units to characterize the resting phase.

The series of parameter regression equations became a part of a larger model that characterizes cumulative bloom as a function of GDD after chilling for any chilling regime between the boundaries of 300 and 1200 chill hours. The boundaries were observed because no data are available to validate the model outside these boundaries. A family of curves generated with the model (Fig. 3), along with historical temperature data from which to calculate GDD, can be used to advise growers about the expected progression of bloom once the chilling period is complete. Specifically, one can project the onset of bloom based on $\gamma$, having units of GDD. The duration of the bloom period is proportional to $\eta$. Together, $\eta$ and $\beta$ indicate more accurately the distribution of flowering over time. Implicit to Eq. [2], parameters $\gamma, \eta$, and $\beta$ provide an estimate (asymptotic maximum) of the cumulative percentage of buds-that will flower over the flowering period.

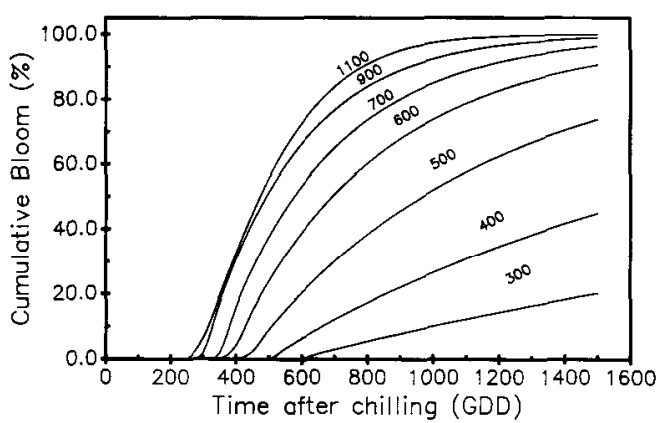

Fig. 3. Predicted cumulative bloom of 'Tifblue' rabbiteye blueberries as a function of GDD after chilling for chilling regimes ranging from 300 to $1100 \mathrm{~h}<7 \mathrm{C}$.
The model was compared to observed flowering data by comparing numerically calculated GDD to $50 \%$ bloom from the model with observed flowering data (Fig. 4). Data were from the current study, Darnell and Davies (1990), and Spiers (1976). The data from the latter two sets were reported on a real time (days) basis and were converted to GDD for comparison. GDD for the two independent experiments were computed using Eq. [1] and mean greenhouse temperatures and days to $50 \%$ bloom reported by the investigators. Errors observed were apparently systematic with respect to the Spiers (1976) data, since the model consistently overestimated GDD to $50 \%$ bloom. Considering the assumptions that were required for calculation and other uncertainties between the investigations, the observed data from the three experiments reveal a marked relationship to the predicted line obtained from the model.

An additional validation was conducted using data from Austin et al. (1982). The relationship reported by them was chilling hour influence on the number of flowers at the end of 30 days, or $480 \mathrm{GDD}$, as calculated using their reported greenhouse temperatures and our Eq. [1]. A total bloom estimate for their data was made using the current model, which indicated that the maximum bloom expected at 480 GDD is $\approx 50 \%$. Therefore, the number of flowers they reported at 850 and 950 chill hours was averaged, and this average was doubled to arrive at an estimated maximum number of flowers for their experimental units. Other flower counts were transformed to percentage of the estimated maximum for comparison. The predicted and observed values for this validation are portrayed in Fig. 5.

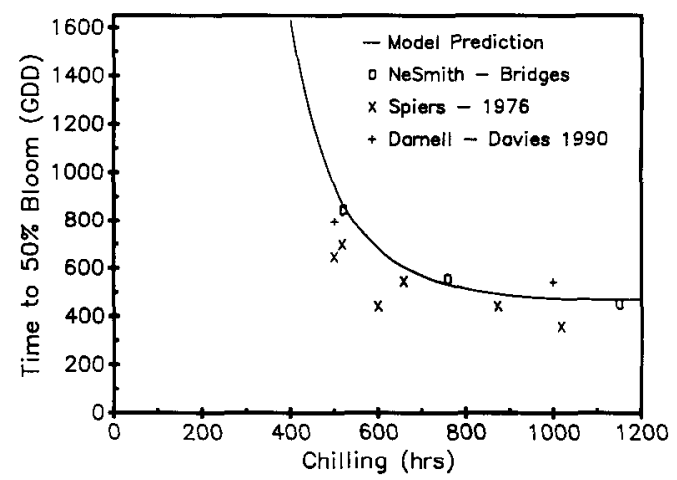

Fig. 4. Predicted and observed GDD after chilling to 50\% bloom for 'Tifblue' rabbiteye blueberries as a function of chilling hours $<7 \mathrm{C}$. Observed data were from the current experiment, Spiers (1976), and Darnell and Davies (1990).

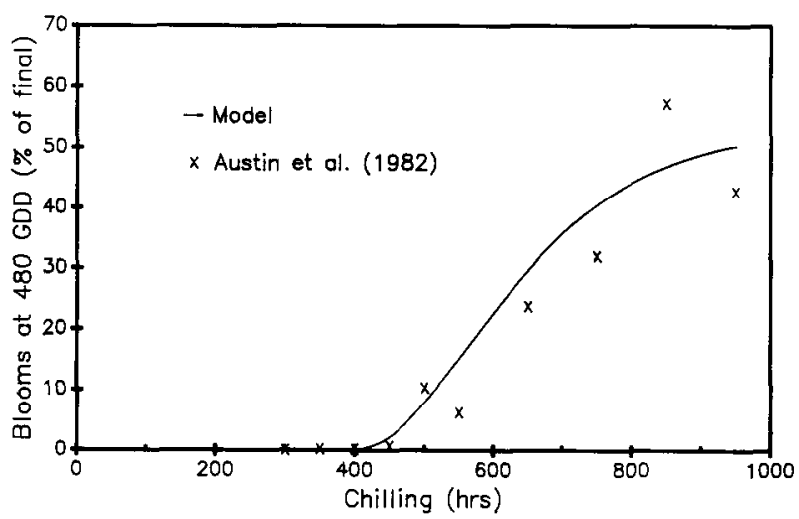

Fig. 5. Predicted and observed percent blooms for 'Tifblue' rabbiteye blueberries at 480 GDD after chilling as a function of chilling hours $<7 C$. Observed data were from Austin et al. (1982). 
The absence of validation data for $<500$ chilling hours illustrates the problem associated with reporting a single-value index such as GDD to $50 \%$ bloom. Our experimental results showed that 'Tifblue' blueberries never reached $50 \%$ bloom when receiving only 350 chilling hours. Likewise, similar results were apparently observed by Spiers (1976) and Darnell and Davies (1990), since they did not report $50 \%$ bloom dates with $<500$ chilling hours.

Given that the model is reasonably accurate, the reported chill requirement of 550 to $650 \mathrm{~h}$ for normal flowering of 'Tifblue' (Austin et al., 1982; Krewer et al., 1989; Spiers, 1976) should not be interpreted as the optimum or maximum floral development response to chilling. The model indicates a continued response of increased rate of bloom development for 'Tifblue' rabbiteye blueberries at chilling durations $>650 \mathrm{~h}$. These results may explain, in part, why 'Tifblue' blueberries that experience $600 \mathrm{~h}$ of chilling in south Georgia or north Florida do not yield as much as those grown further north and which experience more chill hours.

While knowledge of cumulative bloom in response to chilling offers much needed information for grower management, the concentration of blooms at a particular time may often be of interest. An example of a management strategy where information on distribution of bloom would be useful is the timing of applications of gibberellic acid to increase fruit set (NeSmith and Krewer, 1992). Growers would like to treat the most blooms possible with one spray. The probability density of 'Tifblue' bloom as a function of GDD after chilling for selected chilling regimes is portrayed in Fig. 6. The histograms were obtained by taking the derivative of the respective modeled cumulative bloom functions with a specified interval of 50 GDD. The bloom density predictions indicate that as chill hours increase, bloom becomes more concentrated at the lower end of the GDD after chilling scale. Also, with lower chilling, a significant concentration of blooms at any particular interval of GDD becomes less likely.

The model permits a quantitative description of the flowering
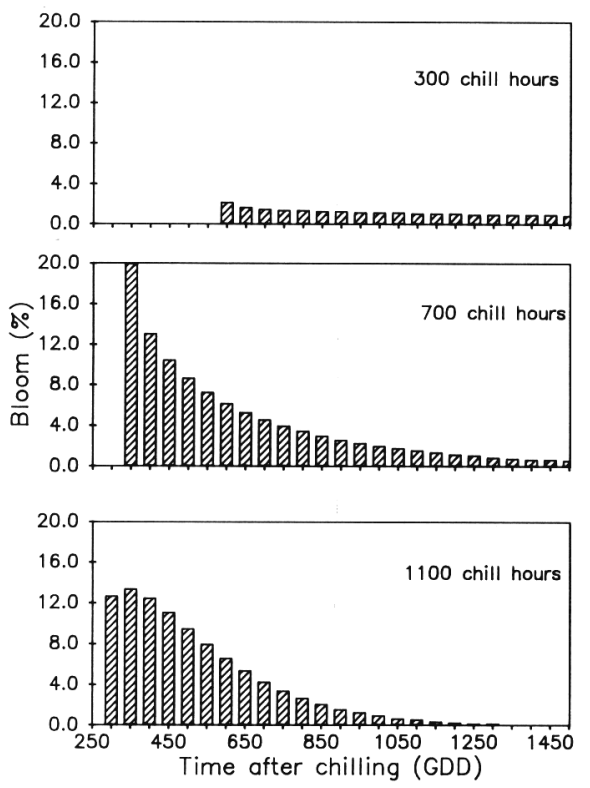

Fig. 6. Predicted bloom distribution for 'Tifblue' rabbiteye blueberries as a function of GDD after chilling for chilling regimes of 300, 700 , and $1100 \mathrm{~h}<7 \mathrm{C}$. The GDD interval at which evaluations were made was 50 . process with respect to chilling hours and thermal units after chilling. The application of thermal units in this research was applied with different intervals for chilling and subsequent development. Chilling was characterized using an hourly interval and was reported as chill hours, whereas subsequent bud development and flowering were characterized with a daily interval and were reported as GDD. The use of GDD for relating flowering to time and temperature was necessitated by the unavailability of data with corresponding hourly temperature records for validation. The interval with which thermal units are accumulated can affect the accuracy with which cumulative flowering or other phenological events are distributed (Bridges et al., 1989; Richardson et al., 1975). Richardson et al. (1974), suggested that the use of growing degree hours (GDH) may be more appropriate for describing peach [Prunus persica (L.) Batsch] bud development. Therefore, future research will need to focus on model sensitivity analyses and validation in which factors such as time-step intervals, base temperature, and starting date will be manipulated.

It is not feasible to conduct extensive whole-plant bud counts to determine the exact chilling requirements for varius fruit cultivars; however, the techniques presented here offer a reasonable alternative to the otherwise laborious task of bud counting. The Weibull function proved well-suited for reconstructing the progression of flowering and for further incorporation into a comprehensive blueberry management model that couples the subsequent developmental processes. The model can be used to predict the onset of flowering; describe cumulative flowering, including duration of the flowering period; predict yield potential as a function of the total number of buds that will flower; and predict flowering frequency during discrete intervals, which is valuable for scheduling pesticide or growth regulator applications or other management practices. Further, the techniques will be applicable to flowering response of other fruits.

\section{Literature Cited}

Anstey, T.H. 1966. Prediction of full bloom date for apple, pear, cherry, peach, and apricot from air temperature data. Proc. Amer. Soc. Hort. Sci. 88:57-65.

Austin, M.E., B.G. Mullinix, and J.S. Mason. 1982. Influence of chilling on growth and flowering of rabbiteye blueberries. HortScience 17:768-769.

Beddows, A.R. 1968. Head emergence in forage grasses in relation to February-May temperatures and the predicting of early or late springs. J. Brit. Grasslands Soc. 23:88-97.

Bridges, D.C. and J.M. Chandler. 1989. A population level temperature-dependent model of seedling johnsongrass flowering. Weed Sci. 37:471-477.

Bridges, D.C., H. Wu, P.J.H. Sharpe, and J.M. Chandler. 1989. Modeling distributions of crop and weed seed germination time. Weed Sci. 37:724-729.

Brown, R.F. 1987. Germination of Aristita armata under constant and alternating temperatures and its analysis with cumulative Weibull distributions as a model. Austral. J. Bot. 35:581-591.

Brown, R.F. and D.G. Mayer. 1988. Representing cumulative germination. 2. The use of the Weibull function and other empirically derived curves. Ann. Bot. 57:49-53.

Cohen, A.C., B.J. Whitten, and Y. Ding. 1984. Modified moment estimation for three-parameter Weibull distribution. J. Quality Technol. 16:159-167.

Couvillon, G.A. and A. Erez. 1985. Influence of prolonged exposure to chilling temperatures on bud break and heat requirement for bloom of several fruit species. J. Amer. Soc. Hort. Sci. 110:47-50.

Darnell, R.L. and F.S. Davies. 1990. Chilling accumulation, budbreak, and fruit set of young rabbiteye blueberry plants. HortScience 25:635-638. 
Gaswiler, J.S. 1971. Emergence and mortality of Douglas-fir, western hemlock, and western red cedar seedlings. For. Sci. 17:230-237.

Ihnen, L.A. and J.H. Goodnight. 1985. The NLIN procedure. SAS user's guide: Statistics, version 5.0, SAS Institute, Cary, N.C. p. 575-606.

Johnson, N.L. and S. Kotz. 1970. Continuous univariate distributions-1. Wiley, New York. p. 250-271.

Krewer, G., S. Myers, P. Betrand, D. Horton, S. Brown, and M. Austin. 1989. Commercial blueberry culture. Univ. of Ga. Coop. Ext. Serv. Circ. 713, Athens, Ga.

Linvill, D.E. 1990. Calculating chilling hours and chill units from daily maximum and minimum temperature observations. HortScience 25:1416.

Lyrene, P.M. and T.E. Cracker. 1983. Poor fruit set on rabbiteye blueberries after mild winters: Possible causes and remedies. Proc. Fla. State Hort. Soc. 96:195-197.

Mann, N.R., R.E. Schafer, and N.D. Singpurwalla. 1974. Methods for statistical analysis of reliability and life data. Wiley, New York.

NeSmith, D.S. and G. Krewer. 1992. Flower bud stage and chill hours influence the activity of GA, applied to rabbiteye blueberry. HortScience 27:316-318.

Richardson, E.A., S.D. Seeley, and D.R. Walker. 1974. A model for estimating the completion of rest for 'Redhaven' and 'Elberta' peach trees. HortScience 9:331-332.

Ritchie, J.T. and D.S. NeSmith. 1991. Temperature and crop development, p. 5-29. In: J. Hanks and J.T. Ritchie (eds.). Modeling plant and soil systems. Amer. Soc. Agron., ASA Monogr. 31., Madison, Wis.

Rom, R.C. and E.H. Arrington. 1966. The effect of varying temperature regime on degree-days to bloom in the Elberta peach. Proc. Amer. Soc. Hort. Sci. 88:239-244.

Sanders, C.G. 1976. Climatic chilling in Georgia. Ga. Agr. Res. 18(1):19-21.

Spiers, J.M. 1976. Chilling regimes affect bud break in 'Tifblue' rabbiteye blueberry. J. Amer. Soc. Hort. Sci. 101:84-86.

Spiers, J.M. and A.D. Draper. 1974. Effect of chilling on bud break in rabbiteye blueberry. J. Amer. Soc. Hort. Sci. 99:398-399.

Veerhoff, 0.1940. Time and temperature relations of germinating flax. Amer. J. Bot. 27:225-231. 